\title{
Prevalence and associated factors of metabolic syndrome and its individual components among adolescents
}

\author{
Getabalew Endazenaw Bekele ${ }^{1}$, Gloria Thupayagale-Tshweneagae ${ }^{2}$ \\ ${ }^{1}$ Department of Social and Population Health, Yekatit 12 Hospital Medical College, Ethiopia \\ ${ }^{2}$ Department of Health Studies, University of South Africa, Pretoria, South Africa
}

\begin{tabular}{l} 
Article Info \\
\hline Article history: \\
Received Nov 9, 2019 \\
Revised Jan 17, 2020 \\
Accepted Feb 22, 2020 \\
\hline
\end{tabular}

Keywords:

Adolescents

Blood pressure

Fasting blood glucose

High-density lipoprotein

Metabolic syndrome

Triglyceride

Waist circumference

\begin{abstract}
Metabolic syndrome is a growing health problem that affects the whole population including adolescents due to change in lifestyles. It is strongly associated with different lifestyle behavioral factors. The objective of the study was to investigate the magnitude and associated factors of metabolic syndrome in adolescents. School based cross-sectional study design was used. The sample size for this study was 844 and 8 high schools were randomly selected from Addis Ababa city Administration. Simple random sampling technique was used to select each participant. Data was analyzed using SPSS version 24 and descriptive summary statistics produced to present the findings. In this study among the components of metabolic syndrome, the highest prevalence was observed in high level of fasting blood glucose level $57.8 \%$, followed by high waist circumference $32.2 \%$. The overall prevalence of metabolic syndrome from the total study participants was $12.4 \%$. Smoking, alcohol intake, performing vigorous or modern physical activity, body mass index and time spent for sedentary activities were factors which had significant association with individual metabolic abnormalities. In conclusions the magnitude of metabolic syndrome is common problem of adolescents in the study area.
\end{abstract}

This is an open access article under the CC BY-SA license.

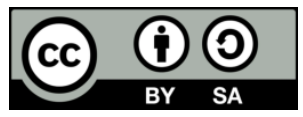

\section{Corresponding Author:}

Getabalew Endazenaw Bekele,

Department of Social and Population Health,

Yekatit 12 Hospital Medical College, Ethiopia.

Email: eyobgetabalew@gmail.com

\section{INTRODUCTION}

Metabolic syndrome is a non-communicable condition, which presents a global public health and clinical challenge and the disease is attributed to behavioural factors such as smoking, poor dietary habits, physical inactivity and sedentary lifestyle [1]. According to IDF, metabolic syndrome is diagnosed based on waist circumference greater than or equal to $90^{\text {th }}$ percentile in combination with any two clinical measures of the following elements: Blood pressure $(\geq 130 / 85 \mathrm{MmHg})$, Glucose (Fasting Plasma Glucose $(\mathrm{FPG}) \geq 100 \mathrm{mg} / \mathrm{dL}$ ), and Lipids (Serum triglyceride $\geq 150 \mathrm{mg} / \mathrm{dL}$ or Serum HDL-C <40 mg/dl) [2, 3].

The incidence and prevalence of metabolic syndrome is high among school going adolescents. In India the incidence of metabolic syndrome among healthy school-going children aged between 16-18 years was $4.79 \%$ [4]. The percentage of students affected by metabolic syndrome in Brazil was $10.2 \%$ with $28.6 \%$ and $23.1 \%$ of the students had one and two metabolic syndrome components respectively. The most frequent metabolic abnormality was high waist circumference (47.6\%) followed by low HDL-C $(24.5 \%)$, high triglyceride $(23.8 \%)$ and $11.6 \%$ of the students were hypertensive. The prevalence of metabolic syndrome is higher among overweight or obese students [5]. According to Mbove, Diaz, 
Wallale, Mazariegos and Jolly, the overall prevalence of metabolic syndrome among primary and secondary school students is $2 \%$ with highest prevalence of high triglyceride level $(43.4 \%)$ followed by low level of HDL-C (17.2) and the least prevalence components of metabolic syndrome are high blood glucose level and high blood pressure. In similar study there is different in the prevalence of overall as well as the individual components of metabolic syndrome by gender of the students. Except the prevalence of triglyceride level, the other entire metabolic syndrome and its components are higher among male students than female students [6].

Researchers reported that more than $20 \%$ of school-going adolescents are overweight, with $16 \%$ and $7 \%$ of the adolescents being overweight and obese respectively. Overweight or obesity is the major risk factor for the development of metabolic syndrome and one or more metabolic abnormalities. Among high school students who had metabolic syndrome $80 \%$ of the students had normal weight obesity (high body fat deposition) and $58 \%$ of the adolescents who had high body fat deposition developed one or more risk factors for metabolic syndrome [7].

Most of the school adolescents have risky lifestyle behaviours that increase their risk to develop metabolic syndrome or its individual components like sedentary and physical inactivity, unhealthy diet, heavy drinking, unhealthy and sleeping pattern. For instance in Iceland most of high school students (89\%) consume one or more types of alcohol. Similarly, $21.4 \%$ and $20.3 \%$ of high school students were current smokers and had sedentary lifestyle respectively [7-9].

The prevalence rate of metabolic syndrome among adolescents in Ethiopia is not well known. In Addis Ababa $8.5 \%$ of high school students were overweight. Similarly, $47.2 \%$ high school students had sedentary lifestyle (spent more than 2 hours per day on television, video game and computer) and $34.6 \%$ of the adolescents had low physical activity habit. High school students who spent much time for sedentary lifestyle, who have low physical activity and eat less fruit and vegetable are more likely to be overweight [10]. In Gambella city, Southwest Ethiopia $13.25 \%$ and $18.21 \%$ of high school students were physically inactive and less active respectively and $6.30 \%$ of the adolescents had overweight or obesity [11]. In central Ethiopia (Adama town and rural Adama woreda) the overall prevalence of overweight in high school students was $10.3 \%$ with $8.5 \%$ overweight and $2.3 \%$ obesity [12].

Metabolic syndrome is strongly associated with different lifestyle behavioural factors. Several studies indicated that the lifestyle of the adolescents like their dietary habit, smoking habit, alcohol consumption, physical activity and sedentary habit are the major contributors for the development of chronic non-communicable diseases including metabolic syndrome. The presence of one unhealthy lifestyle contributed to the development of another unhealthy lifestyle. For example, smoking contributes to the development of alcohol drinking, physical inactivity and poor dietary habit [13]. According to Chu et al, metabolic syndrome has significant association with the body mass index (BMI) and waist circumference of the adolescents. The prevalence of metabolic syndrome was 13.7 times higher in male adolescents who had BMI greater than $90^{\text {th }}$ percentile when compared to male adolescents who had normal body mass index and for every one unit BMI increasing the prevalence of metabolic syndrome increased by 1.43 times. The male adolescents who had a higher waist circumference were 20.9 times more likely affected by metabolic syndrome than male adolescents who had normal waist circumference and for every one centimeter increasing of waist circumference metabolic syndrome increased by 1.16 times. Similarly female adolescents who had BMI greater than $90^{\text {th }}$ percentile were 26 times more likely affected by metabolic syndrome than female adolescents who had normal BMI and for every one unit increasing in BMI the prevalence of metabolic syndrome increased by 1.50 times. Girls who had higher waist circumference 23 times were more likely develop metabolic syndrome than girls who had normal waist circumference and for every one centimeter increasing in waist circumference metabolic syndrome increased by 1.19 times [14]. Efforts to identify adolescents at risk of developing metabolic syndrome to prevent or mitigate its associated outcome have been active areas of research within adolescent's population.

\section{RESEARCH METHOD}

The study was conducted in Addis Ababa city administration of Governmental high schools. School based cross-sectional survey was conducted from October 1-15, 2016. The source and study population- all students who were enrolled in 2016/2017 academic year in high schools found in the study area of Addis Ababa city administration were taken as source population and students who were enrolled in 2016/2017 academic year in selected schools were taken as study population.

Multistage sampling was used. First 3 sub-cities were selected randomly among 10 sub-cities of Addis Ababa. In the second stage 8 high schools were selected randomly from the selected 3 sub-cities. In the third stage the selected schools were further stratified into grade and finally proportional sample size were allocated to each grade and the grade further stratified in into sections. The sections from each grade 
were randomly selected. The data collectors were provided with a number for each student based on alphabetical order to prepare a sampling frame. After that, simple random sampling technique was used to select the required number of adolescents. The sample size was determined using single population proportion formula by the assumption that $50 \%$ of the adolescents had metabolic syndrome with $5 \%$ marginal error and $95 \% \mathrm{CI}$ and multiplying by design effect 2 due to the multi stage nature of the sampling technique. Then adding none response rate of $10 \%$. Based on this assumption the final representative sample size was 844 .

The questionnaire for collecting data was developed through reviewing WHO STEP wise approach for non-communicable diseases surveillance. The questionnaire consisted of four parts. Part I-socio-demographic variables of the study participants, Part II behavioural variables of the study participants (dietary behaviour, physical activity habit, alcohol consumption habit and smoking habit), part III-physiological measures of the study participants (height, weight, waist circumference and blood pressure) and part IV - biochemical measures of the study participants (fasting blood glucose level, serum total cholesterol level, serum triglyceride level, and serum high-density lipoprotein level). After the study participants had completed part I and part II, the physiological and biochemical measures were taken. The height of the adolescent was measured in standing erect position using standometer with $0.1 \mathrm{~cm}$ resolution. The weight of the participants was measured using beam balance with barefoot and wearing light clothes with $0.1 \mathrm{~kg}$ resolution. The waist circumference was measured using measuring tape of $0.1 \mathrm{~cm}$ resolution from midpoint between the last rib and iliac crest. The students sat upright with his/her right upper arm positioned at the level of the heart with both feet flat on the floor. Systolic and diastolic arterial blood pressure were obtained using a stethoscope and a mercury sphygmomanometer after 5 minutes rest and repeated measures were taken after 2 minutes additional rest. The mean score was recorded as the blood pressure of the students. Blood sample was collected by nurses in the schools compound. The blood glucose level was measured immediately by using sensocard plus blood glucose meter and sensor card. The collected blood sample to measure lipid profile was stored at $2-8^{0} \mathrm{C}$ in iceboxes and then transported to the Afenicho ber health center laboratory for analysis within 6 hours of collection. The lipid profile (total cholesterol, triglyceride, high-density lipoprotein) was analyzed using biosystem A 25 automotive chemistry machine and human reagent.

The questionnaires were pre-tested on 42 (5\% of the sample size) adolescents who were not involved in the main study. All anthropometric measurement and laboratory measurement equipment were checked every time before new measurements are taken. The data collectors were trained and supervised throughout the data collection period and the questionnaire was checked every day for completeness.

The data were checked for completeness and consistency. Data were then coded and captured into a personal computer using the Statistical Package for Social Sciences software (SPSS) version 24.0 Data was analyzed and descriptive summary statistics produced to present the findings. The result of the study was presented in graph, Table and text based on thematic areas. Bivariate analysis was done to identify the factors associated with metabolic abnormalities.

Ethical clearance was obtained from University of South Africa and Addis Ababa Health Bureau IRB as well a formal letter was prepared and submitted to the selected high schools to get their permission. The researcher was provided all the necessary information about the research protocol and procedures for the study participants and obtained their informed consent from adolescents who were 18 years and above. For those adolescents whose age was less than 18 year's age, information about the research protocol and procedure were given for the adolescents and their parent and informed consent was obtained from their parent and assent from the adolescents. In this research the privacy and confidentiality of the participants were ensured throughout the process of the research.

\section{RESULTS AND DISCUSSION}

\subsection{Result}

A total of 824 adolescents from 8 secondary schools in Addis Ababa City administration participated with the response rate of $97.6 \%$. More than half (421) $(51.1 \%)$ of the participants were female, whereas the remaining were male adolescents. The mean age of the adolescents was $16.59 \pm 1.36 \mathrm{SD}$ with the minimum age of 13 years of age and the maximum age of 19 years. The majorities 769 (93.3\%) of the adolescents were in the age group of 15-19 years. Most of the adolescents $789(95.8 \%)$ were single whereas $10(1.2 \%)$ of them were married in their marital status. Regarding the educational status of the adolescents was $321(39.0 \%)$ grade $9216(26.2 \%)$ grade 10, $130(15.8 \%)$ grade 11 and the rest were grade 12 . Three hundred sixty five $(44.3 \%)$ of the adolescents' parent were private workers $233(27.1 \%)$ government workers and $85(10.3 \%)$ were non-governmental organization worker. The median monthly income of the adolescents' parent was 2800 Ethiopian birr. Three hundred forty two (41.5\%) 
and $227(27.5 \%)$ of the parents of the adolescents had more than 3000 and less than 1500 Ethiopian birr monthly income respectively Table 1.

Table 1. The pattern of alcohol consumption by sex and education level of secondary school students

\begin{tabular}{|c|c|c|c|}
\hline \multirow{3}{*}{ Variables } & \multicolumn{2}{|c|}{ Alcohol consumption } & \multirow{3}{*}{ Total } \\
\hline & Yes & No & \\
\hline & No $(\%)$ & No $(\%)$ & \\
\hline \multicolumn{4}{|l|}{ Sex } \\
\hline Male & $108(13.1)$ & $295(35.8)$ & $403(48.9)$ \\
\hline Female & $76(9.2)$ & $345(41.9)$ & $421(51.1)$ \\
\hline Total & $184(22.3)$ & $640(77.7)$ & $824(100)$ \\
\hline \multicolumn{4}{|c|}{ Educational status } \\
\hline Grade 9 & $44(5.3)$ & 277 (33.6) & $321(39.0)$ \\
\hline Grade 10 & $53(6.4)$ & $163(19.8)$ & $216(26.2)$ \\
\hline Grade 11 & $27(3.3)$ & $103(12.5)$ & $130(15.8)$ \\
\hline Grade 12 & $60(7.3)$ & $97(11.8)$ & $157(19.0)$ \\
\hline Total & $184(22.3)$ & $640(77.7)$ & $824(100)$ \\
\hline
\end{tabular}

\subsubsection{Lifestyle behaviour of the adolescents}

History of alcohol consumption, history of smoking, physical exercise, vegetable and fruit consumption of the adolescents were assessed. Alcohol consumption habit of the adolescents had variation by their gender and educational level. Out of the total number of respondents, $303(36.8 \%)$ of the respondents consumed alcohol and $184(22.3 \%)$ of them had current alcohol consumption whereas the rest of the adolescents had not taken any alcoholic drink. Among the current drinkers, more than half $108(58.3 \%)$ were male adolescents and the rest $(41.3 \%)$ were female adolescents. The pattern of alcohol consumption by the educational level of the students, $44(5.3 \%), 53(6.4 \%) 27(3.3 \%)$ and $60(7.3 \%)$ of current drinkers were in grade 9, grade 10, grade 11 and grade 12 respectively. Regarding the history of smoking, $68(8.3 \%)$ was currently smoking. Among the current smokers, more than half $37(54.4 \%)$ were female and $31(45.6 \%)$ of them were male students. Two hundred eighty-seven $(34.8 \%)$ and $107(13.0 \%)$ of the adolescents were exposed to smoking in the school or working environment, and in their home respectively. Among the current smokers $42(5.1 \%)$ of them smoked 1-5 cigarette sticks per day and the remaining $26(3.2 \%)$ smoked more than 5 cigarette sticks per day. Physical activity habit of the adolescents also had variation by gender of the adolescents. Male adolescents were slightly physically active than female adolescents. According to the responses, 365 (44.3\%) of them perform vigorous or moderate physical activity whereas $459(55.7 \%)$ of them were physically inactive (did not perform vigorous or moderate physical activity). Based on the time spent doing vigorous or moderate physical activity per week 195 (23.7\%), $125(15.2 \%)$ and $45(5.5 \%)$ of the adolescents had low physically activity (spent less than 150 minutes/week), medium physically active (spent from 150-300 minutes/week) and highly physically active (spent more than 300 minutes/week) respectively. The majority $(n=739 / 89.7 \%)$ of the adolescents are used to walking or cycling. The adolescents spend 4.69 \pm 2.19 SD mean days per week and $82 \pm 78$ SD of mean minutes per week for walking or cycling activities. Among unhealthy lifestyles of adolescents widely practiced by school adolescents in the study area was spent much time for sedentary activities. Most of the adolescents $679(82.4 \%)$ spend more than 2 hours per day for sedentary activities. Two hundred twenty-six (27.4\%) of the adolescents eat vegetable and fruit 1-3 days per week and the rest of the adolescents eat vegetables and fruits four or more days per week. Majority of the adolescents 497 (60.3) did not eat food prepared outside their home whereas $192(23.3 \%)$ of them eat food prepared outside their home 1-3 days in a week Table 2 and Figure 1.

\subsubsection{Metabolic syndrome and its individual components}

Among the components of metabolic syndrome the highest prevalence was observed in high level of fasting blood glucose level (FBG) followed by high waist circumference (WC). From the total participants $476(57.8 \%) 265(32.2 \%) 216(26.2), 170(20.6 \%), 95(11.5 \%)$ and $70(8.5 \%)$ of the adolescents had high level of fasting blood glucose level, high waist circumference, high triglyceride level, low level of high density lipoprotein cholesterol, high level of total cholesterol and high blood pressure respectively. The overall prevalence of metabolic syndrome from the total study participants was $102(12.4 \%)$. The prevalence of metabolic syndrome had difference by the age of adolescents i.e. the prevalence was higher in the age group of 15-19 years of adolescents than adolescents in the age group of 10-14 years of age $98(11.9 \%)$ vs $4(0.5 \%)$. Among the total study participants the majority $669(81.2 \%)$ of them had at least one or more metabolic abnormalities. One abnormality 325 (39.4\%), two abnormalities 214 (26.0\%),

\footnotetext{
Prevalence and associated factors of metabolic syndrome and its individual (Getabalew Endazenaw Bekele)
} 
three abnormalities $87(10.6 \%)$, four abnormalities $32(3.9 \%)$ and five abnormalities $11(1.3 \%)$ were developed by the adolescents in the study area. The overall prevalence of overweight/obesity had variation by sex and age of the adolescents. The mean body mass index was $20.96 \mathrm{~kg} / \mathrm{m}^{2} \pm 3.46$ SD. The overall prevalence of overweight or obesity was $109(13.2 \%)$. When assessing the prevalence of overweight and obesity separately, $97(11.8 \%)$ and $12(1.4 \%)$ of the adolescents were overweight and obese in the study area respectively Table 3 and Figure 2.

Table 2 . The pattern of smoking by sex among secondary school students

\begin{tabular}{|c|c|c|c|}
\hline \multirow{2}{*}{ History of smoking } & \multicolumn{2}{|c|}{ Sex } & \multirow{2}{*}{ Total } \\
\hline & Male No $(\%)$ & Female No (\%) & \\
\hline \multicolumn{4}{|l|}{ Current smoking } \\
\hline Yes & $31(3.8)$ & $37(4.5)$ & $68(8.3)$ \\
\hline No & $372(45.1)$ & $384(46.6)$ & $756(91.7)$ \\
\hline Total & $403(48.9)$ & $421(51.1)$ & $824(100.0)$ \\
\hline \multicolumn{4}{|l|}{ Exposed to smoking in the house } \\
\hline Yes & $50(6.1)$ & $57(6.9)$ & $107(13.0)$ \\
\hline No & $353(42.8)$ & $364(44.2)$ & $717(87.0)$ \\
\hline Total & 403 (48.9) & $421(51.1)$ & $824(100.0)$ \\
\hline \multicolumn{4}{|c|}{ Exposed to smoking in the school or outside the home } \\
\hline Yes & $153(18.6)$ & $134(16.3)$ & $287(34.8)$ \\
\hline \multirow[t]{2}{*}{ No } & $250(30.3)$ & $287(34.8)$ & $537(65.2)$ \\
\hline & 403 (48.9) & $421(51.1)$ & $824(100.0)$ \\
\hline \multicolumn{4}{|l|}{ Physical activity habit } \\
\hline \multicolumn{4}{|l|}{ Vigorous or moderate physical activity } \\
\hline Yes & $199(24.2)$ & $166(20.1)$ & $365(44.3)$ \\
\hline No & $204(24.8)$ & $255(30.9)$ & $459(55.7)$ \\
\hline Total & $403(48.9)$ & $421(51.1)$ & $824(100.0)$ \\
\hline \multicolumn{4}{|l|}{ Time spent for physical activity } \\
\hline Inactive (no physical activity) & $204(24.8)$ & $255(30.9)$ & $459(55.9)$ \\
\hline Low active $(<150$ minute/week $)$ & $117(14.2)$ & $78(6.5)$ & $195(23.7)$ \\
\hline Medium active (150-300 minute/week) & $55(6.7)$ & $70(8.5)$ & $125(15.2)$ \\
\hline High active (>300 minute/week) & $27(3.3)$ & $18(2.2)$ & $45(5.5)$ \\
\hline Total & $403(48.9)$ & $421(51.1)$ & $824(100.0)$ \\
\hline \multicolumn{4}{|l|}{ No of days/week for physical activity } \\
\hline No physical activity & $204(24.8)$ & $255(30.9)$ & $459(55.9)$ \\
\hline $1-3$ days & $113(13.7)$ & $87(10.6)$ & $200(24.3)$ \\
\hline$>3$ days & $86(10.4)$ & $79(9.6)$ & $165(20.0)$ \\
\hline Total & $403(48.9)$ & $421(51.1)$ & $824(100.0)$ \\
\hline
\end{tabular}

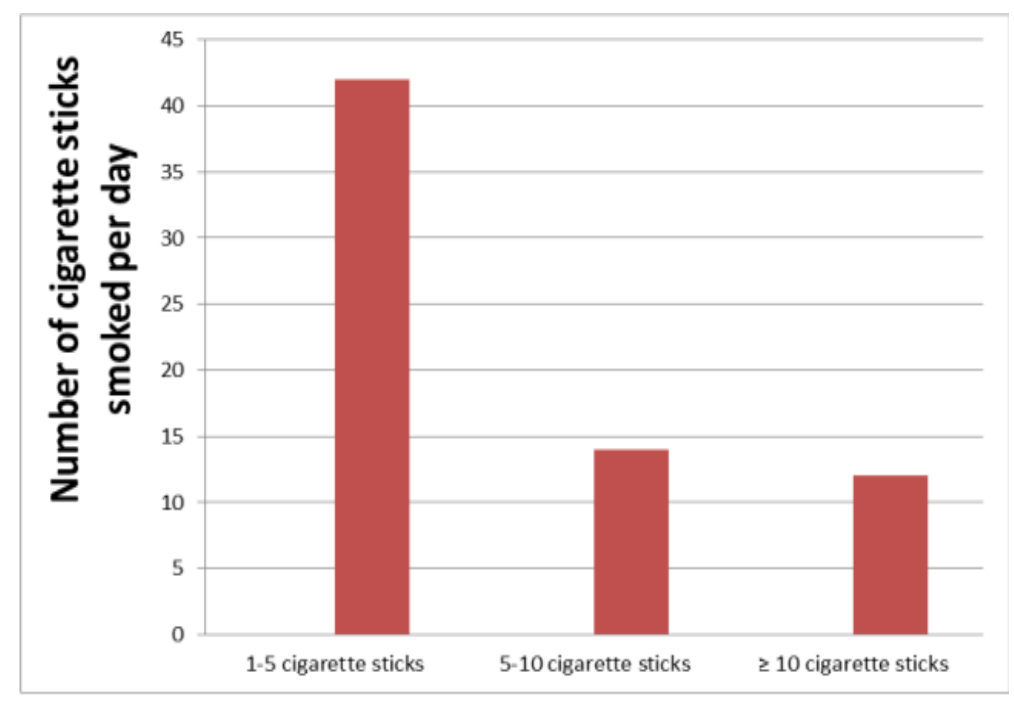

Figure 1. Number of cigarette sticks smoked per day by secondary school students 
Table 3. The pattern of metabolic syndrome components among high school students

\begin{tabular}{|c|c|c|c|c|c|}
\hline $\begin{array}{l}\text { Metabolic syndrome } \\
\text { components }\end{array}$ & Number & $\%$ & $\begin{array}{l}\text { Metabolic syndrome } \\
\text { components }\end{array}$ & Number & $\%$ \\
\hline Fasting blood glucose level & & & $\geq 40 \mathrm{mg} / \mathrm{dl}$ & 654 & 79.4 \\
\hline$<100 \mathrm{mg} / \mathrm{dl}$ & 348 & 42.2 & Total cholesterol level & & \\
\hline$\geq 100 \mathrm{mg} / \mathrm{dl}$ & 476 & 57.8 & $<200 \mathrm{mg} / \mathrm{dl}$ & 729 & 88.5 \\
\hline Waist circumference & & & $\geq 200 \mathrm{mg} / \mathrm{dl}$ & 95 & 11.5 \\
\hline$<90^{\text {th }}$ percentile & 559 & 67.8 & Blood pressure & & \\
\hline$\geq 90^{\text {th }}$ percentile & 265 & 32.2 & $<135 / 85 \mathrm{mmHg}$ & 754 & 91.5 \\
\hline Triglyceride level & & & $\geq 135 / 85 \mathrm{mmHg}$ & 70 & 8.5 \\
\hline$<150 \mathrm{mg} / \mathrm{dl}$ & 608 & 73.8 & Metabolic syndrome status & & \\
\hline$\geq 150 \mathrm{mg} / \mathrm{dl}$ & 216 & 26.2 & Yes & 102 & 12.4 \\
\hline High density lipoprotein level & & & No & 722 & 87.6 \\
\hline$<40 \mathrm{mg} / \mathrm{dl}$ & 170 & 20.6 & Total & 824 & 100 \\
\hline
\end{tabular}

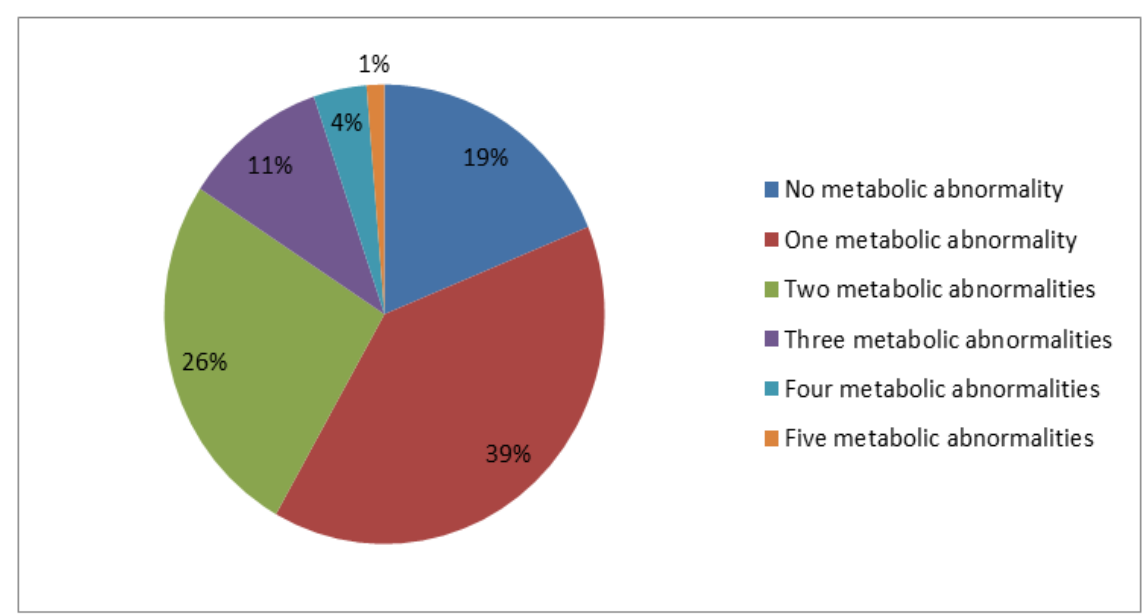

Figure 2. Number of metabolic abnormalities developed by high school students

According to bivariate analysis sex, smoking, alcohol intake (both ever intake and current intake), performing vigorous or modern physical activity, body mass index, time spent for sedentary activities were factors, which had statistical significant association with metabolic syndrome. The findings of this study showed that adolescents who were practiced different types of unhealthy lifestyle behaviours were more subjected to develop metabolic syndrome when compared to their counterparts. Female adolescents were at high risk of developing metabolic syndrome than male adolescents. In this study, female adolescents were 1.5 times more at risk to develop metabolic syndrome when compared to their counterpart. Adolescents in the age group of 15-19 years were at high risk to develop metabolic syndrome but age was not statistically associated with metabolic syndrome. Metabolic syndrome had no significant association of the educational status of the adolescents Table 4. Metabolic syndrome had statistically significant association with the lifestyles of adolescents in the study area. Adolescents with smoking experience/habit were at high risk to develop metabolic syndrome. In this study non-smoker adolescents were at less risk to develop metabolic syndrome by $54 \%$ than smoker adolescents. Similarly, those who do not drink alcoholic beverages were less likely to develop metabolic syndrome by $36 \%$ and $48 \%$ respectively than their counterpart. Adolescents who had a habit of performing vigorous or moderate physical activities were at less risk to develop metabolic syndrome than adolescents who did not practice physical activity. According to the finding of this research, adolescents who did not perform vigorous or did moderate physical activity were 1.56 times more at risk to develop metabolic syndrome than adolescents who performed vigorous or moderate physical activities. On the other hand, adolescents who spent more time not involved in physical activities were at high risk of developing metabolic syndrome than their counter parts. For example, adolescents who spent more than 2 hours per day on sedentary activities were 2.12 times more likely to develop metabolic syndrome than adolescents who spent less than 2 hours per day in sedentary activities. The other factor, which had statistical significant association with metabolic syndrome, was body mass index of the adolescents. Overweight and obese adolescents were 10.59 times and 12.75 times more likely to develop metabolic syndrome when compared to adolescents who had normal body mass index in the study area Table 4.

Table 4. Factors associated with metabolic syndrome among secondary school adolescents

Prevalence and associated factors of metabolic syndrome and its individual (Getabalew Endazenaw Bekele) 


\begin{tabular}{|c|c|c|c|}
\hline \multirow{2}{*}{ Variables } & \multicolumn{2}{|c|}{ Metabolic syndrome status } & \multirow{2}{*}{ OR with $95 \% \mathrm{CI}$} \\
\hline & Metabolic syndrome N (\%) & Non-metabolic syndrome N (\%) & \\
\hline \multicolumn{4}{|l|}{ Sex } \\
\hline Male & $41(5.0)$ & $362(43.9)$ & 1 \\
\hline Female & $61(7.4)$ & $360(43.7)$ & $1.50(0.981,2.281)^{*}$ \\
\hline \multicolumn{4}{|l|}{ Educational status } \\
\hline Grade 9 & $44(5.3)$ & 277 (33.6) & 1 \\
\hline Grade 10 & $30(3.6)$ & $186(22.6)$ & $1.02(0.616,1.674)$ \\
\hline Grade 11 & $12(1.5)$ & $118(14.3)$ & $0.64(0.326,1.256)$ \\
\hline Grade 12 & $1691.9)$ & $141(17.1)$ & $0.71(0.389,1.311)$ \\
\hline \multicolumn{4}{|l|}{ Age in year } \\
\hline $10-14$ & $4(0.5)$ & $51(6.2)$ & 1 \\
\hline $14-19$ & $98(11.9)$ & $671(81.4)$ & $1.86(0.658,5.266)$ \\
\hline \multicolumn{4}{|l|}{ Smoking } \\
\hline Yes & $15(1.8)$ & $53(6.4)$ & 1 \\
\hline No & $87(10.6)$ & $669(81.2)$ & $0.46(0.248,0.850)^{*}$ \\
\hline \multicolumn{4}{|l|}{ Alcohol drinking (ever) } \\
\hline Yes & $47(5.7)$ & $256(31.1)$ & 1 \\
\hline No & $55(6.7)$ & $466(56.6)$ & $0.64(0.423,0.977)^{*}$ \\
\hline \multicolumn{4}{|l|}{ Current alcohol drinking } \\
\hline Yes & $34(4.1)$ & $150(18.2)$ & 1 \\
\hline No & $68(8.3)$ & $572(69.4)$ & $0.52(0.335,0.822)^{*}$ \\
\hline \multicolumn{4}{|c|}{ Vigorous or modern physical activity } \\
\hline Yes & $55(6.7)$ & $310(37.6)$ & 1 \\
\hline No & $47(5.7)$ & $412(50.0)$ & $1.56(1.026,2.358)^{*}$ \\
\hline \multicolumn{4}{|l|}{ BMI } \\
\hline Normal & $52(6.3)$ & $663(80.5)$ & 1 \\
\hline Overweight & $44(5.3)$ & $53(6.4)$ & $10.59(6.489,17.267)^{*}$ \\
\hline Obesity & $6(0.7)$ & $6(0.7)$ & $12.75(3.972,40.927)^{*}$ \\
\hline \multicolumn{4}{|c|}{ Time spent for sedentary activity } \\
\hline$\leq 2$ hour/day & $10(1.2)$ & $135(16.4)$ & 1 \\
\hline$>2$ hour/day & $92(11.2)$ & $587(71.2)$ & $2.12(1.073,4.172)^{*}$ \\
\hline \multicolumn{4}{|l|}{ activity } \\
\hline$\leq 2$ hour/day & $10(1.2)$ & $135(16.4)$ & 1 \\
\hline$>2$ hour/day & $92(11.2)$ & $587(71.2)$ & $2.12(1.073,4.172)^{*}$ \\
\hline
\end{tabular}

Means P-valve less than 0.05

\subsection{Discussion}

In this study the researcher assessed the lifestyle behaviours of adolescents and prevalence of metabolic syndrome. A remarkable proportion of the adolescents had a history of alcohol consumption. Previous studies in the adolescents' pattern of alcohol use supported this study. In a study by Ujunwa et al on use of alcohol by adolescents found that adolescents use alcohol, but the prevalence was slightly higher than the prevalence of the current study [15]. The prevalence of smoking was comparable with the studies done in different countries. For example in Malaysia the prevalence of smoking among adolescents ranges from $7.45 \%$ to $8.8 \%[16,17]$. Similarly in Asian countries from $4.1 \%$ to $8.8 \%$ of the adolescents had experience of smoking $[14,18]$.

Even though a large proportion of adolescents performed vigorous or moderate physical activity, still more than half of the adolescents were physically inactive. Among those who performed moderate to vigorous physical activity, the majority of the adolescents spent less than 150 minutes per week and only few adolescents spent more than 300 minutes per week for moderate to vigorous physical activities. Male adolescents spent more time engaging in physical activities when compared to female adolescents. According to Canfield, adolescents spent 51 minutes per day for physical activity in cumulative and similar to alike the current study male adolescents were spent more time for physical activity than female adolescents [19]. Most of the adolescents (82.4\%) spent more than two hours per day on sedentary activities. According to Gebreyohannes et al, $47.2 \%$ of the adolescents in Addis Ababa spent more than 2 hours per day for sedentary activities like watching television, playing video game and computer [10]. Thus the prevalence of sedentary lifestyle (the proportion of adolescents spent more than 2 hours per day for different sedentary activities) in the current study was higher than the finding of the study conducted [10].

Metabolic syndrome and its individual components were the common health problem of adolescents in the study area. Based on IDF definition $12.4 \%$ of the adolescents were affected by metabolic syndrome. 
According to the findings of different studies conducted indifferent parts of the world the overall prevalence of metabolic syndrome ranges from $2.1 \%$ to $9.8 \%$ [20-24]. This indicates that the prevalence of metabolic syndrome was higher in the current study when compared to the above-mentioned studies. Therefore, metabolic syndrome is the common public health problem of the adolescents in the study area, but the prevalence of metabolic syndrome in the current study was lower than the finding of study done in Tunisia [25]. Even if the overall prevalence of metabolic syndrome was only $12.4 \%$, of the most of the adolescents $(81.2 \%)$ had at least one metabolic abnormality. Among those who had metabolic abnormality, the majority of the adolescents had one abnormality followed by two and three metabolic abnormalities. According to the research findings in a study [5], metabolic syndrome affected a remarkable proportion $(10.2 \%)$ of the adolescents with $28.6 \%$ and $23.1 \%$ of the adolescents affected by one or two metabolic abnormalities in Brazil respectively, but the overall prevalence and the proportion of adolescents affected by one and two metabolic abnormalities were higher in this study when compared with the study conducted in Brazil. On the other hand, the overall prevalence of metabolic syndrome in the current study was lower than the study findings done in Morocco (18.6\%) and Egypt $(20 \%)$ of the adolescents had metabolic syndrome [26, 27]. In this study, the prevalence of individual components of metabolic syndrome was assessed and the prevalence ranged from $57.8 \%$ to $8.5 \%$. More than half of the adolescents $(57.8 \%) \mathrm{had}$ fasting blood glucose level greater or equal to $100 \mathrm{mg} / \mathrm{dl}$ of blood. Based on the findings of different studies conducted in different countries the prevalence of high blood glucose level ranged from $1.7 \%$ to $16.5 \%[19,22,26,28]$. More than $32 \%$ of the adolescents in Addis Ababa (this study) had waist circumference greater or equal to $90^{\text {th }}$ percentile. High waist circumference was the second most common prevalent metabolic abnormality of the adolescents found in this study. According to Burrows et al, $33.3 \%$ of the Chilean adolescents had high waist circumference. The proportion of the adolescents with high waist circumference in the current study was slightly lower than the proportion of the adolescents with high wait circumference in Chile [24].

The third most common prevalent metabolic abnormality in the study area was high triglyceride (greater or equal to $1500 \mathrm{mg} / \mathrm{dl}$ ) level. More than $26 \%$ of the adolescents had triglyceride level greater or equal to $150 \mathrm{mg} / \mathrm{dl}$. According to Carvalho et al and Tope and Rogers, $20.9 \%$ and $11.2 \%$ of the adolescents had high triglyceride level. Thus, the proportion of the adolescents who had blood triglyceride level greater or equal to $150 \mathrm{mg} / \mathrm{dl}$ in the current research was higher than the findings of the studies done by Carvalho et al and Tope and Rogers [29, 30].

More than $20 \%$ of the adolescents had high-density lipoprotein less than $40 \mathrm{mg} / \mathrm{dl}$. This indicates having low level of high-density lipoprotein also common metabolic abnormality of the adolescents in Addis Ababa city administration. The prevalence of low HDL-C (high-density lipoprotein) in Chile (69.9\%) was more than three times higher from the prevalence of the current research finding [24]. According to the study done in Cameron $49.3 \%$ of the adolescents had high-density lipoprotein less than 40mg/dl which was higher than the finding of this study [31]. A similar condition was observed in South Sudan in which $41.4 \%$ of the students had high-density lipoprotein less than $40 \mathrm{mg} / \mathrm{dl}[32]$.

The mean body mass index of the adolescents was in the normal range, but $13.2 \%$ of the adolescents were either overweight or obese. The prevalence of overweight $(11.8 \%)$ was higher than the prevalence of obesity $(1.4 \%)$. The prevalence of overweight differed by gender. Based on study done by Gebreyohannes et al in Addis Ababa $8.5 \%$ of the adolescents were overweight [10]. Thus the prevalence of overweight in the current study was higher than the prevalence of overweight from the previous study. According to Sain et al, the prevalence of overweight (16.73\%) and obesity (6.54\%) in India was higher than the prevalence of overweight and obesity in the current study [33]. On the other hand, the trend of overweight increased in Addis Ababa city administration. The prevalence of overweight and obesity in the current study was also higher than that of other studies done in Central Ethiopia. In Central Ethiopia 10.8\% of the adolescents were affected by overweight or obesity with $8.5 \%$ of the adolescents were overweight and $2.3 \%$ of them were obese [12].

Metabolic syndrome is strongly associated with different lifestyle behavioural factors. Smoking and alcohol consumption habit were predictors of metabolic syndrome. Smoking and drinking adolescents were at higher risk to develop metabolic syndrome than their counterparts. Non-smoking adolescents had less probability of developing metabolic syndrome by $54 \%$ when compared with smoking adolescents. According to Balhara, use of any form of tobacco increase the prevalence of metabolic syndrome and any of the components of metabolic syndrome [34]. Participating in vigorous or moderate physical activity decreased the adolescents' risk to develop metabolic syndrome. Adolescents who did not involve in moderate or vigorous physical activity were 1.56 times at high risk to develop metabolic syndrome compared to adolescents involved in moderate or vigorous physical activity. Performing vigorous or moderate physical activity was significantly associated with triglyceride level but not associated with rest of metabolic syndrome components. Adolescents who spent more time doing physical activity were at less risk to develop 
metabolic syndrome. For example in a study done in junior high school students in Ho Chi minh city, adolescents who spent less than 43 minutes for physical activity were five times more likely to develop metabolic syndrome when compared with adolescents spent more than 103 minutes per day for physical activity [35]. Spending much time on sedentary activity increased the probability of developing metabolic syndrome. Adolescents spent more than 2 hours per day on sedentary activity were 2.12 times at higher risk to develop metabolic syndrome compared to adolescents spent less than or equal to 2 hour per day for sedentary activity. Adolescents who spent much time on sedentary activities are at a high risk of developing high waist circumference, high blood pressure high lipid profile [36]. Overweight and obesity were major predictors of metabolic syndrome. Overweight and obese adolescents were 10.59 times and 12.75 times at higher risk to develop metabolic syndrome respectively compared to normal weight adolescents. Body mass index had statistical significant association with total cholesterol level, triglyceride level, waist circumference, high-density lipoprotein and blood pressure of the adolescents, but BMI was not associated with fasting blood glucose level of the adolescents. In this study, the prevalence of individual components of metabolic syndrome was more commonly observed in overweight and obese adolescents. Thus, overweight and obesity were among the risk factors that increased the development of metabolic abnormalities in adolescents. This finding was consistence with the study done by Nişancı-Kılınç and Çağdaş [37] that revealed overweight or obese adolescents were more affected by individual components of metabolic syndrome. Based on the study conducted in Bruit body mass index of the adolescent had statistical significant association with metabolic syndrome, triglyceride, and blood pressure. For instance BMI was significant predictor of metabolic syndrome with odd ratio of 1.255 at $95 \% \mathrm{CI}=1.144-1.377$ [38].

\section{CONCLUSION}

In conclusion, metabolic syndrome and individual metabolic abnormalities were common public health problems of the adolescents in Addis Ababa. Among the total participants 12.4\% of adolescents had metabolic syndrome. Most (81.2\%) of adolescents had at least one metabolic abnormality. Regarding the prevalence of individual metabolic syndrome, the most prevalent metabolic abnormality was high fasting blood glucose $(57.8 \%)$ followed by high waist circumference $(32.2 \%)$, high triglyceride $(26.2 \%)$ and $20.6 \%$ low HDL cholesterol level. The overall prevalence of overweight and obesity was $13.2 \%$. Based on the finding we recommend the school and the health sector should work or strengthen the school health services that focus on lifestyle behaviors and metabolic syndrome of the adolescents. We also recommend researchers to conduct community based research on metabolic syndrome.

\section{ACKNOWLEDGEMENTS}

We would like to express our sincere gratitude to University of South Africa to give us this prodigious chance to conduct this research. Our special thanks also go to selected schools for their cooperation and assistance throughout the process of the research. At last but not least we want to give our deepest gratitude for all friends and study participants who are helping us throughout the process of the research.

\section{REFERENCES}

[1] Giday, T, Aseffa, H \& Kidanemariam, A, "Assessment of risk factors associated with type II diabetes mellitus in central zone of Tigray north Ethiopia," International Journal of Pharmaceutical and Biological Sciences Fundamentals, vol. 7, no. 1, pp.1-20, 2014

[2] International Diabetes Federation (IDF), "The IDF consensus definition of the metabolic syndrome in children and adolescent," IDF, 2007.

[3] Bahat, RA, Parray, SM \& Ahmad, O., "Prevalence of metabolic syndrome among north Indian adolescents using adult treatment panel III and pediatric International Diabetes Federation," Journal of Diabetes and Metabolism, vol. 5, pp.352, 2014.

[4] Mahajan, N, Kumari, A \& Kshatriya, GK., "Prevalence of metabolic syndrome in adolescents of India and the associated risk factors: A systematic review," Human Biology Review, vol. 5, no. 4, pp. 2277-4424, 2016.

[5] Rinaldi, AEM, Gabriel, GFCP, Moreto, F, Corrente, JE, McLellan, KCPM \& Burini, RC., "Dietary factors associated with metabolic syndrome and its components in overweight and obese Brazilian schoolchildren: aAcross-sectional study," Diabetics and Metabolic Syndrome, vol. 8, no. 58, pp. 1-10, 2016.

[6] Mbowe, O, Diaz, A, Wallace, J, Mazariegos, M \& Jolly, P., "Prevalence of metabolic syndrome and associated cardiovascular risk factors in Guatemalan school children," Maternal Child Health Journal, vol. 8, no. 7, pp. 1619-1627, 2014.

[7] Olafsdottir, AS, Torfadottir, JE \& Arngrimsson, SA., "Health behavior and metabolic risk factors associated with normal weight obesity in adolescents," PLOS ONE, vol. 11, no. 8, pp. 1-15, 2016. 
[8] Tachang, GK, Pierrre, SC, Jules, D, Ndzudie, T, \& Titanj, VPK., "Effect of lifestyle options on the determinants of the Metabolic Syndrome in the urban and peri-urban Regions of Cameron," International Journal of Medicine and Medical Sciences, vol. 4, no. 5, pp. 158-168, 2014.

[9] Andreadis, EA, Tsourous, GI, Tzavara, CK, Georgiopoulos, DX, Katsanou, PM, Marakomichelakis, GE \& Diamantopoulos, EJ., "Metabolic syndrome and incident cardiovascular morbidity and mortality in a mediterranean hypertensive population,” American Journal of Hypertension, vol. 20, pp. 558-564, 2007.

[10] Gebreyohannes, Y, Shiferaw, S, Demtsu, B \& Bugssa, G., "Nutritional status of adolescents in selected government and private secondary schools of Addis Ababa, Ethiopia," International Journal of Nutrition and Food Sciences, vol. 3, no. 6, pp. 504-514, 2014.

[11] Megersa, DG, Abebe, SM, Abebe, FM \& Wassie, MM., "Prevalence and associated factors of low serum zinc concentration in adolescents of Gambella city, Southwest Ethiopia," Nutrition and Dietary Supplements, vol. 9, pp. 1-8, 2017.

[12] Wakayo, T, Whiting, SJ \& Belachew, T., "Vitamin D deficiency is associated with overweight and/or obesity among schoolchildren in central Ethiopia: A cross-sectional study," Nutrients, vol. 8, no. 190, pp. 1-12, 2016.

[13] Rabaeus, M, Salen, P \& Lorgeril, MD., "Is it smoking or related lifestyle variables that increase metabolic syndrome risk? BMC Medicine," 2013 Available from [Online] http://www.biomedcentral.com/1741-7015/11/196 (accessed 15 November 2015).

[14] Chu, N-F, Chin, H-C \& Wang, SC., "Prevalence and anthropometric risk of metabolic syndrome in Taiwanese adolescents," International Scholarly Research Network Cardiology vol. 1, pp. 4-16, 2011.

[15] Ujunwa, FA, Ikefuna, AN, Nwokocha, AR \& Chinawa, J., "Hypertension and prehypertension among adolescents in secondary schools in Enugu, South East Nigeria," Italian Journal of Pediatrics, vol. 39, pp. 2-4, 2013.

[16] Hazreen, MA, Su, TT, Jalaludin, MY, Dahlui, M, Chinna, K, Ismail, M, Murray, L, Cantwell, M, Al Sadat, N and MyHeART Study Group, "An exploratory study on risk factors for chronic non-communicable diseases among adolescents in Malaysia: Overview of the Malaysian health and adolescent's longitudinal research team study. The MyHeART study," BMC Public Health, vol. 14, no. 3, pp. 6, 2014.

[17] Dahlui, MN, Jahan, NK, Majid, HA, Jalaludin, MY, Murray, L, Cantwell, M, Su, TT, Al-Sadat, N and MyHeARTs Group, "Risk and protective factors for cigarette use in young adolescents in a school setting: What could be done better?," PLoS ONE, vol. 10, no. 6, pp. 4, 2015.

[18] Kim, SJ, Lee, J, Nam, CM \& Lee, SY., "Impact of obesity on metabolic syndrome among adolescents as compared with adults in Korea," Yonsei Medical Journal, vol. 52, no. 5, pp. 746-752, 2011.

[19] Canfield, J., "Models of physical activity and sedentary behavior. Doctor of Philosophy," Syracuse University. 2012.

[20] MacPherson, M, Groh, MD, Loukine, L, Prud'homme, D \& Dubois, L., "Prevalence of metabolic syndrome and its risk factors in Canadian children and adolescents: Canadian health measures survey Cycle 1 (2007-2009) and Cycle 2 (2009-2011)," Health Promotion and Chronic Disease Prevention in Canada Research, Policy and Practice, vol. 36, no. 2, pp. 32-40, 2016.

[21] Kyscgubur, NCC, Bloch, KV, Szklo, M, Klein, CH, Barufaldi, LA, Abreu, GA, Schaan, V Veiga, G, Silva, H \& Vasconcellos. A., "ERICA: Prevalence of metabolic syndrome in Brazilian adolescents," Review Saude Publications, vol. 50, no. 1, pp. 1s-11s, 2016.

[22] Neto, AS, Sasaki, JE, Mascarenhas, LPG, Boguszewski, MCS, Bozza, R, Ulbrich AZ, Da Silva, SG \& De Campos W., "Physical activity, cardiorespiratory fitness, and metabolic syndrome in adolescents: A cross-sectional studu," BMC Public Health, pp. 1-8, 2011.

[23] Usha, SMR, Chandrika, N, Shetty, HV \& Reena, R., "A study of the components of metabolic syndrome in young adults," Biomedical Research, vol. 25, no. 1, pp. 45-50, 2014.

[24] Burrows, R, Correa-Burrows, P, Reyes, M, Blanco, E, Albala, C \& Gahagan, S., "High cardiometabolic risk in healthy Chilean adolescents: associations with anthropometric, biological and lifestyle factors," Public Health Nutrition, vol. 19, no. 3, pp. 486-493, 2015.

[25] Regaieg, S, Charfi, N, Kamoun, S, Eulleuch, M, Marrakchi, R, Jamoussi, K, Damak, J \& Abid, M., "Prevalence of metabolic syndrome and its components among overweight and obese secondary school adolescent in SFAX, Tunisia," International Journal of Clinical Nutrition, vol. 3, no. 1, pp. 1-6, 2015.

[26] Hamrani, A, Mehdad, S, EI-Kari, K, EI-Hamdouchi, A, Barkat, A, Belghiti, E, EI-Mzibri, B, EI-Haloui, H, Mokhtar, SA \& Aguenaou, HM., "Prevalence of metabolic syndrome and its individual components among Moroccan adolescents: The role of overweight-obesity and excess body fat," Journal of Metabolic Syndrome, vol. 2, pp. 129, 2013.

[27] Zaki, ME, El-Bassyouni, HT, El-Gammal, M \& Kama, S. Indicators of the metabolic syndrome in obese adolescents, Archvives of Medical Science, vol. 11, no. 1, pp. 92-98, 2015.

[28] DeBoer, MD \& Gurka, MJ., "Low sensitivity of the metabolic syndrome to identify adolescents with impaired glucose tolerance: An analysis of NHANES 1999-2010," BMC Cardiovascular Diabetolog. 2014. Available from [online]: http://www.cardiab.com/content/13/1/83 (accessed 27 October 2015).

[29] Carvalho, RB, Nobre, RS, Guimarães, MR, Teixeira, SE \& Silva AR., "Risk factors associated with the development of metabolic syndrome in children and adolescents," Acta Paulista Enfermagen, vol. 29, no. 4, pp. 439-445, 2016.

[30] Tope, AM \& Rogers, PF., "Metabolic syndrome among students attending a historically black college: Prevalence and gender differences," Diabetology and Metabolic Syndrome, vol. 5, no. 2, pp. 1-8, 2013 
[31] Ngo-Song, MC, AzantsaKingue, BG, Fouejeu-Wamba, PC, Abega-Ebene, PJ, Ngondi, J.L \& Oben JE., "Prevalence of metabolic syndrome among 16-21 years urban cameronian using NCEP ATPIII and IDF Criteria," British Journal of Medicine and Medical Research, vol. 4, no. 13, pp. 2483-2493, 2014.

[32] Sabir, FM, Hassan, DA \& Elamin, MI., "Prevalence of metabolic syndrome among young sudanese university students using three different criteria of WHO, IDF and NCEP-ATP III," Pediatric Neonatal Nursing Open Acces,. vol. 2, no. 2, pp. 1-11, 2016.

[33] Sain, S, Mukhopadhya, P, Saha, TK, Yasmin, S, Chatterji, A \& Dey, I., "Adolescent Obesity: its correlates and associated morbidity," Global Journal of Medicine and Public Health, vol. 2, no. 6, pp. 1-7, 2013.

[34] Balhara, YP., "Tobacco and metabolic syndrome," Indian Journal of Endocrinology Metabolism, vol. 16, no. 1, pp. 81-87. 2012.

[35] Nguyen, THHD, Tang, HK, Kelly, PK, Van der Ploeg, HP \& Dibley, MJ., “Association between physical activity and metabolic syndrome: a cross sectional survey in adolescents in Ho Chi Minh City, Vietnam," BMC Public Health, vol. 10, no. 141, pp. 1-8, 2010.

[36] Fletcher, E, Leech, R, McNaughton, SA, Dunstan, DW, Lacy, KE \& Salmon, J., "Is the relationship between sedentary behaviour and cardio metabolic health in adolescents independent of dietary intake? A systematic review," Obesity Review, vol. 16, no. 9, pp. 795-805, 2015.

[37] Nişanc1-Kılınç, F \& Çağdaş, DN., "Diet and physical activity interventions do have effects on body composition and metabolic syndrome parameters in overweight and obese adolescents and their mothers," The Turkish Journal of Pediatrics, vol. 55, no.3, pp. 292-299, 2013.

[38] Nasreddine, L, Naja, F, Tabet, M, Habbal, MZ, El-Aily, A, Haikal, C, Sidani, S, Adra, N \& Hwalla, N., "Obesity is associated with insulin resistance and components of the metabolic syndrome in Lebanese adolescents," Annals of Human Biology, vol. 39, no. 2, pp. 122-128, 2012. 